\title{
Transient Stability Enhancement of Grid by Using Fuzzy Logic Based Statcom
}

\author{
Anil Antony P. ${ }^{1}$, R.Punitharaji ${ }^{2}$ \\ 1. P.G.Student, Paavai Engineering College, Namakkal. \\ 2. Assistant Professor/EEE, Paavai Engineering College, Namakkal.
}

\begin{abstract}
This paper proposes Fuzzy Logic Based STATCOM. It regulates the voltage at the point of common coupling (PCC) by injecting reactive power. This device also plays a vital role in enhancing stability for small and large transient disturbances in power system. Simulations using MATLAB / SIMULINK are carried out to verify the performance of STATCOM using fuzzy controller. The result shows that fuzzy logic controller is a better choice for the STATCOM compared to the PI controller. Fuzzy logic controller forces the system to return back the steady state value faster than the PI controller. The fuzzy logic controller is robust and has a fast response during disturbance and parameters variation. Detailed study of control of STATCOM has been made, which include analysis of PLL, VSC, mathematical dq transformation has been explained.
\end{abstract}

Keywords-Static Synchronous Compensator (STATCOM), Pulse-Width Modulation (PWM), Fuzzy logic controller (FCL), PLL, Regulator,abcto dq transformation, Voltage Source Converter (VSC)

\section{Introduction}

Transients are always present at each and every movement. During transients voltage level at the grid gets changed rapidly causing voltage stability problems. The change in voltage at the grid causes rotor angle to deviate this will cause angle stability problems. Both the voltage and angle are permitted to vary with in some limits, if it crosses the limits whole the system will get highly unstable. Our power system consist of many number of generators connected to the grid. Once the stability of any one of the generating unit gets disturbed, it will gradually disturbs stability of other units connected to the system which that may leads to Cascade tipping which in turn can causes blackouts.

FACTS controllers can be used to control instabilities caused by transients. STATCOM is one of the FACTES controller, which is capable of supplying or absorbing reactive power to maintain grid voltage [1][3].it consist of control circuit, voltage source converter (VSC), dc capacitor and coupling transformer. VSC consist of power electronic devices which are being triggered to perform reactive power transform between grid and STACTCOM.

Here IGBT's are used in VSC, for triggering the gate of IGBT pulse width modulation technique (PWM) is being used [4]. The input to the PWM generator is controlled by control unit, which uses fuzzy logic as its controlling technique.Phase lock loop (PLL) has been used to track the phase angle of grid which helps in synchronising control unit.[5]-[8]

The STATCOM is normally designed to provide fastvoltage control to enhance the stability of system. Two basic controls are implemented in a STATCOM [2],[3]. The first is the AC voltage regulation across the gridand second one is the control of the DC voltage across the capacitor. By using the above controller the active powerinjection from the STATCOM to the grid is being controlled.

Conventionally PI controllers have been use as regulates of STATCOM.Conventional PI controller has limitation over its operating range. It is highly inefficient during nonlinear operations. Fuzzy logic controller eliminates the limitations of conventional PI controller [9]-[11].

Mathematical transformation of three phase vector fromabc co-ordinate axis to synchronously rotating $\mathrm{dq}$ axis has been applies for reducing the circuit complexity and easy analysis of the circuit.

\section{The Static Synchronous Compensator (Statcom)}

STATCOM from the name itself is a power compensation device, which is capable of compensating reactive power and real power as well, depending on the circuit configuration. It acts as a shunt compensator. The basic circuit of STATCOM consist of voltage source converter (VSC), control unit and DC energy source (mostly capacitor) for VSC. STATCOM is coupled with the grid by using a coupling transformer 


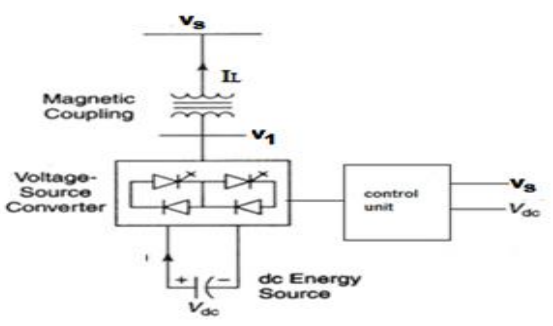

Fig 1: STATCOM basic circuit

In a conventional VSC, a voltagesource is connected at the converter dc side. However, in the case where only reactive power has to be controlled, capacitor of suitable rating is used instead of voltage source. For the compensation of active power, an energy storage system has to be connected at the dc side of the VSC. A small reactor $\left(\mathrm{X}_{\mathrm{L}}\right)$ connected between VSC and the ac network, which is necessary to avoid current peaks during switching transients. In most cases, these reactorsare the leakage inductance of the coupling transformers. During transient situation, STATCOM operates for a short time until the system returns to stable condition.

\section{a. Basic working principle of STATCOM}

In the above given figure $1, \mathrm{Vs}$ is the grid voltage and $\mathrm{V}_{1}$ is the STATCOM voltage. During transients, voltage at the grid varies. To bring the system back to stable condition, voltage at the grid has to be maintained constant. This is done by transfer of reactive power between STATCOM and grid.

The basic principle behind the transfer of reactive power between STATCOM and grid can be explained by given condition and vector diagram given below.

1. Whenever grid voltage is equal to STATCOM voltage $\left(\mathrm{Vs}=\mathrm{V}_{1}\right)$ no power flow will occur between STATCOM and grid (shown in Fig 2a)

2. Whenever the grid voltage is higher than STATCOM voltage ( $\left.\mathrm{V}_{s}>\mathrm{V}_{1}\right)$, STATCOM absorbs reactive power from the grid (shown in Fig 2b). Hence reactive power is inductive in nature.

3. Whenever grid voltage is less than STATCOM voltage $\left(\mathrm{V}_{s}<\mathrm{V}_{1}\right)$, STATCOM supplies reactive power (shown in Fig 2c).Hence reactive power is capacitive in nature.
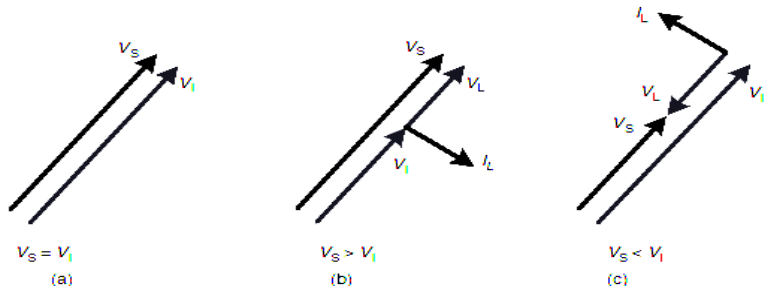

Fig 2: reactive power control in STATCOM

The reactive power supplied by the STATCOM is given

$Q=V_{S}\left[\frac{V_{S}-V_{1}}{V_{1}}\right]$

The above three conditions are explained by considering that STATCOM voltage and grid voltage are in phase, hence only reactive power can be transferred between them.

Whenever there is a phase difference $\delta$ between $V_{S}$ and $V_{1}$ active power transfer take place between STATCOM and grid.

1. If phase difference $\delta$ is positive(shown in Fig 3a), the resultingline current is in such a way that it produces an active power flowinginto the converter, charging the dc capacitor.

2. If phase difference $\delta$ is negative (shown in Fig 3b), active power will flow from the converter to grid that meansthe dc capacitor will get discharged.

Therefore, by controllingthe phase angle $\delta$, it is possible to control the dc capacitorvoltage.
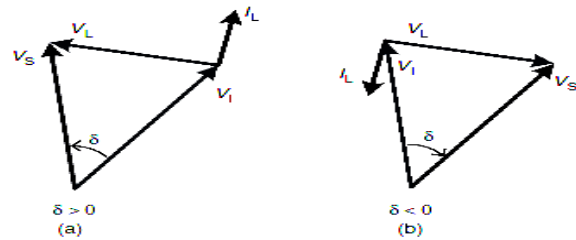

Fig 3: Active power flow in STATCOM 
The real power exchange between STATCOM and the system is given by $P=\frac{V_{S} V_{1}}{X_{L}} \sin (\delta)$

\section{b. Basic Control Techniques}

The basic controlling Technique used by STATCOM is that, it adjusts it's the terminal voltage, in such a way that reactive power is absorbed or injected to the grid to maintain the grid voltage to its nominal value. That is

If the grid voltage is equal to nominal grid voltage, STATCOM terminal voltage will get adjusted to grid voltage by adjusting the firing angle of gates used in VSC (assuming that grid voltage and STATCOM voltage are in phase).

1. If the grid voltage is greater than its nominal grid voltage, STATCOM terminal voltage will be adjusted to a lower value than grid such that it will be capable of absorbing reactive power and bring the grid voltage to its nominal value

2. If the grid voltage is less than its nominal grid voltage, STATCOM terminal voltage will be adjusted to a higher value than grid such that it will be capable of supplying reactive power and bring the grid voltage to its nominal value

From the above it is clear that operation of STATCOM is based on controlling STATCOM terminal voltage. For controlling STATCOM terminal voltage, we need a control unit. Designing control unit forms the main part of this paper.The main parts of a STATCOM are

1. Voltage Source Converter

2. Control unit for STATCOM

3. PWM Generator

1. Voltage Source Converter (VSC): three phases VSC consist of six switches connected as shown in figure 4. The switches connected to same leg of the inverter (S1 and S4, S3 and S6, or S5 and S2) cannot be switched on simultaneously because this would result in a short circuit across the dc link voltage supply. Similarly, in order to avoid undefined states in the VSC, the switches of any leg of the inverter cannot be switched off simultaneously. By using six switches we can have eight switching topology. Out of eight valid states, two of them produce zero ac line voltages in this case the ac line currents freewheel through either the upper or lower components. The selection of the states in order to generate the required waveform is done by the modulating technique.

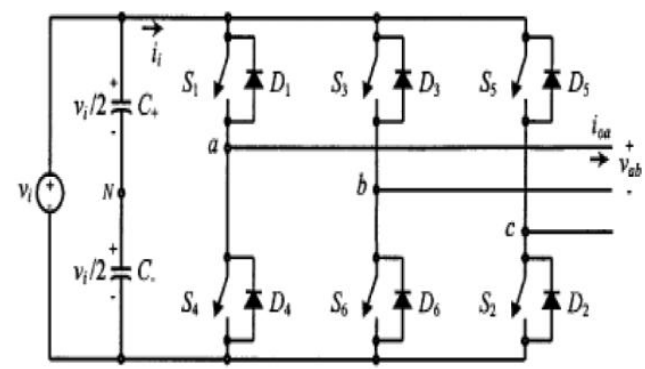

Fig 4: Voltage source converter

The switches of VSC are GTOs (they could be IGBTs, IGCTs, or other self-commutating switches) with an antiparallel-connected diode, which will operates with a unidirectional voltageblocking capability and a bidirectional current flow.

2. Control Unit for STATCOM:Control unit forms the brain of STATCOM. Parameters selectedfor controlling STATCOM terminal voltageare grid voltage, grid current and STATCOM input DC voltage (across capacitor or DC link voltage).Here we use a DC capacitor which acts as DC source for voltage source converter (VSC). To maintain the DC input voltage of VSC, a constant value (voltage across capacitor), DC voltage across the capacitor is taken as one of the parameter for controlling. By adjusting the firing angle of the converter, STATCOM terminal voltage can be varied. So the setting of firing of STATCOM forms the key part of STATCOM controller design. Following are the main parts of STATCOM control unit.

1. $\mathrm{ABC}$ to $\mathrm{DQ}$ conversion algorithm

2. Phase look loop (PLL) 
3. Regulator

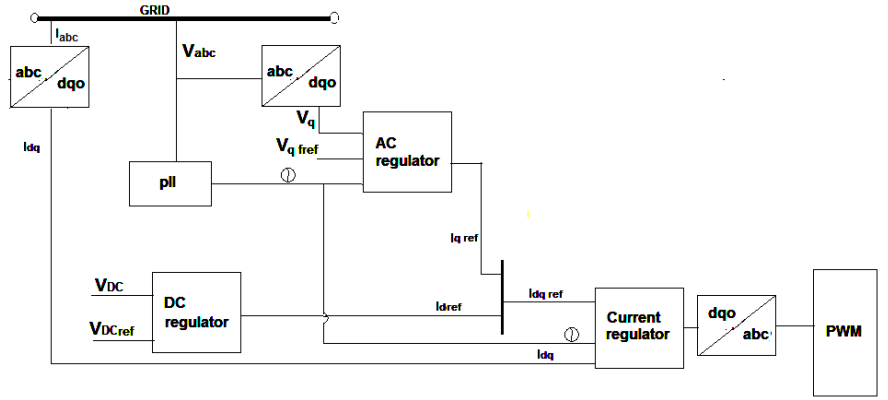

Fig5: Control unit of STATCOM

\subsection{ABC to DQ conversion algorithm}

Normally STATCOM is complex to design. One of the reasons is that during design procedurewe have to consider each phase separately and during transients there will be harmonics in all the three phases, which in turn make the analysis complex. Secondly the circuit will become more complex. Some of these limitations can be overcome by mathematical transformation of three phase AC vectors in to two phase rotatingdq axis vector.In dq-frameunder steady-state conditions, the signals are assumed to have DCwaveforms.

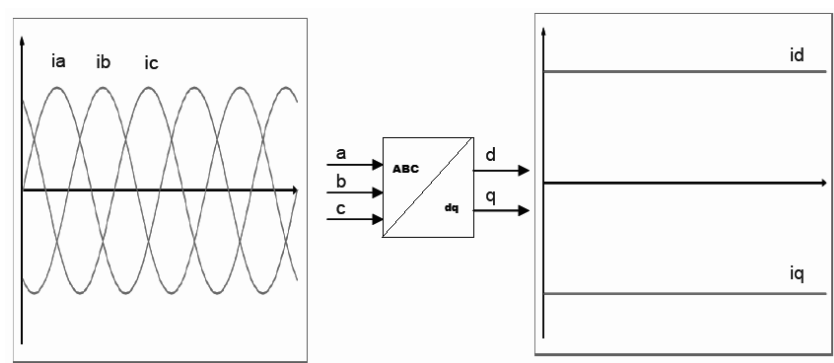

Fig 6: Wave forms in $\mathrm{ABC}$ and dq axis

In dq transformation, vectors in ABC reference axis which is displaced by $120^{\circ}$ are transformed in two perpendicular axis and both the axis itself is assumed to be rotating at the same speed of supply frequency hence the name synchronous rotating frame. Since both $\mathrm{d}$ axis and $\mathrm{q}$ axis are rotating at the same speed of supply frequency, vectors in those axis will be having constant magnitude and phase, hence appears to be DC. Whenever there is any disturbance in $\mathrm{AC}, \mathrm{DC}$ waveform in dq axils will gets disturbed. Hence analysis and control can be done easily in synchronous rotating frame. And reduction of three parameter(inabc axis) to two parameter (in dq axis) reduces the complexity in circuit.

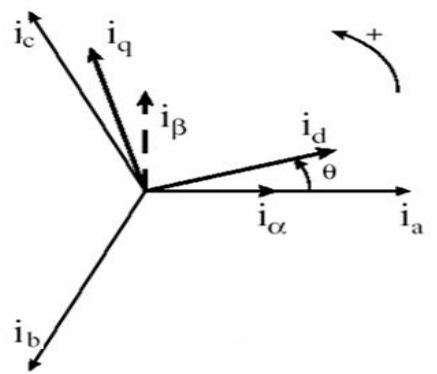

Fig 7: Vector diagram in abc and dq axis

Transformation algorithm is given by

$$
\left[\begin{array}{l}
i_{d} \\
i_{q}
\end{array}\right]=\frac{2}{3} *\left[\begin{array}{ccc}
\sin (\theta) & \sin \left(\theta-\frac{2 \pi}{3}\right) & \sin \left(\theta+\frac{2 \pi}{3}\right) \\
\cos (\theta) & \cos \left(\theta-\frac{2 \pi}{3}\right) & \cos \left(\theta+\frac{2 \pi}{3}\right)
\end{array}\right] *\left[\begin{array}{l}
i_{a} \\
i_{b} \\
i_{c}
\end{array}\right]
$$

\subsection{PLL.}

The PLL adjusts the phase of locally generated signal to match the phase of an input signal. This is used to synchronise control unit with grid parameter 
The basic scheme of PLL consists of three block units

1. Phase Detector (PD), It generates signal proportional to the phase difference between input signal and the signal generated by internal oscillator called VCO.

2. The task of Loop Filter (LF), it is to attenuate the high-frequency components from PD output.

3. Voltage Controlled Oscillator (VCO), it generates a periodic signal, whose frequency is shifted with respect to a given basic frequency. It forms the output of PLL

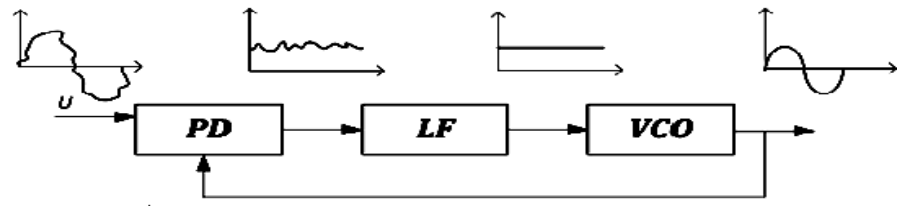

Fig 8: Basic PLL structure

Due to voltage variations phase detection by direct methods can lead to significant errors. PLL in natural coordinates are not sufficiently immune to grid voltage variations a hence coordinates transformation to dqcoordinates are done, which assures proper filtration from distortions. PLL in dqcoordinates is called Synchronous Rotation Frame PLL

\subsubsection{PLL in dqsynchronous rotating coordinates (SRF-PLL)}
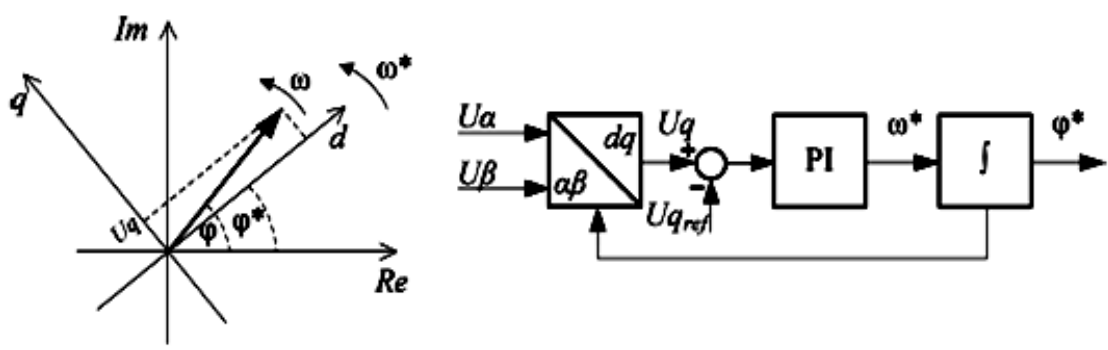

Fig 9: SRF-PLL

Here voltage signals are transformed to Synchronous Rotation Frame (SRF), during steady state output of Synchronous Rotation Frame will be a DC signal. During disturbance in grid will cause disturbance in direct and quadrature axis parameters.

The PI controller adjusts estimated frequency $\omega^{*}$, by controlling Uq to be zero, so that d-axis follows grid voltage vector. Phase angle ${ }_{\varphi}^{*}$ is obtained by integrating frequency and is used for coordinate's transformation. Any distortion of grid voltage, particularly negative voltage sequence becomes $2^{\text {nd }}$ harmonic component will be reflected in synchronous rotating voltage vector. It causes variation of estimated phase angle resulting in improper coordinate's transformation.

To overcome the above problem SRF-PLL with LPF can be used. However due to its slow dynamic response and of chance of phase shift is introduced to signal, Moving Average Filter had been used with in SRFPLL. Circuit diagram of three phase discrete SRF-PLL is given below

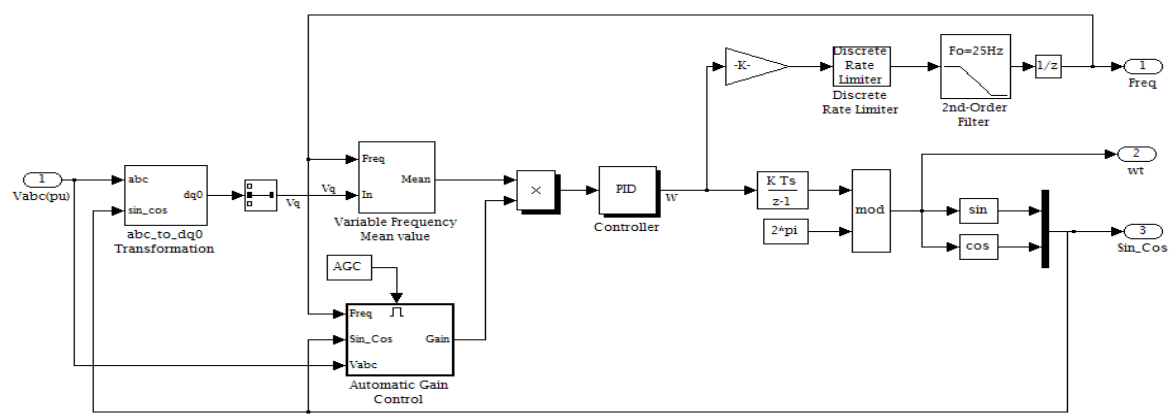

Fig 10: Discrete 3 Phase PLL

\subsection{Regulator}

In the control circuit we can find three regulators,

1. AC voltage regulator 
2. DC voltage regulator.

3. Current regulators

AC Voltage regulator will set quadrature axis reference current and DC voltage regulator sets direct axis reference current. And current regulator will form the input for PWM. These regulators will be normally PI controller, PID controller or any artificial intelligence control technique like fuzzy controller, neuro-fuzzy etc.

DC link voltage is kept constant by controlling the active power flowing to/from the converter. DC link voltage is compared with the DC link voltage reference and DC link voltage error is processed in DC voltage regulator. ThereforeDC voltage regulator determines the phase angle of the converter voltage with respect to source voltage. DC link voltage is determined according to highest STATCOM fundamental voltage in the operation

\subsection{Fuzzy Logic Controller (Flc)}

The main disadvantage of conventional PI controller is its inability to react to abrupt changes in the error signal, $\varepsilon$, because it is inefficient during nonlinear variations. Fuzzy logic controller is much efficient in dealing with nonlinearities. The determination of the output control signal is done in an inference engine with a rule base having if-then rules. With the rule base, the value of the output is changed according to the value of the error signal $\varepsilon$, and the rate-of-error $\Delta \varepsilon$. The structure and determination of the rule base is done using trial-anderror methods and is also done through experimentation.

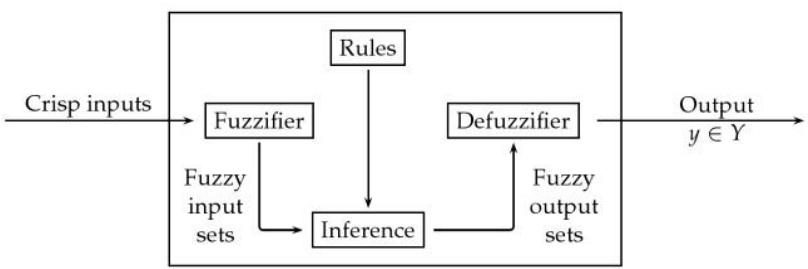

Fig 11: Fuzzy logic controller

The MATLAB/SIMULINK implementation of the fuzzy controller for one phase is shown in figure below

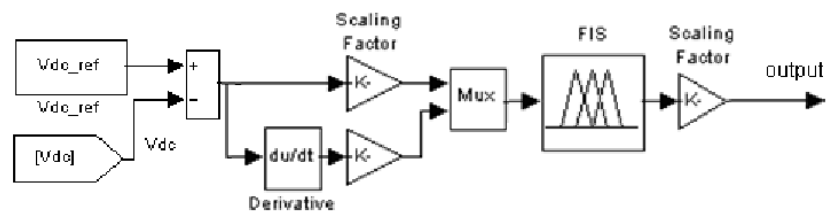

Fig 12: MATLAB implementation of the fuzzy controller

All the variables' fuzzy subsets for the inputs $\varepsilon$ and $\Delta \varepsilon$ are defined as (NB, NM, NS, Z, PS, PM, PB). The membership functions and the universes of the inputs are illustrated in Figure 13. For the output variable, the fuzzy subsets of the membership functions have a triangular shape only as it is illustrated in Figure 14. The fuzzy control rule is illustrated in the tables I.

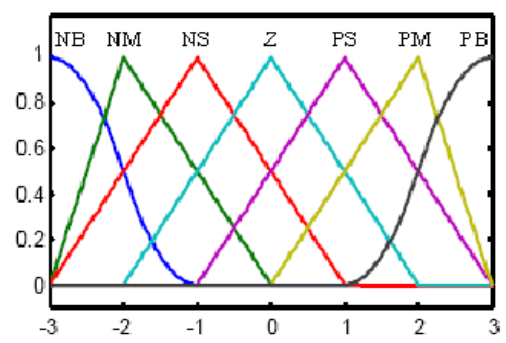

Fig 13: Input membership function

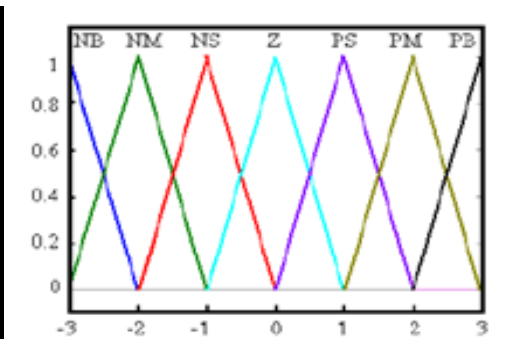

Fig 14: Output membership function

\begin{tabular}{|c|c|c|c|c|c|c|c|}
\hline $\boldsymbol{\varepsilon} / \boldsymbol{\Delta} \boldsymbol{\varepsilon}$ & NB & NM & NS & $\mathbf{Z}$ & PS & PM & PB \\
\hline NB & PB & PB & PM & PM & PS & PS & Z \\
\hline NM & PB & PB & PM & PM & PS & Z & NS \\
\hline NS & PM & PM & PM & PS & Z & NS & NM \\
\hline Z & PM & PS & PS & Z & NS & NM & NM \\
\hline PS & PS & PS & Z & NS & NS & NM & NM \\
\hline PM & PS & Z & NS & NM & NM & NM & NB \\
\hline PM & Z & NS & NS & NM & NM & NB & NB \\
\hline
\end{tabular}




\section{Pwm Generator}

Pulse-width modulation (PWM) of a signal source involves the modulation of its duty Cycle, to control the amount of Power sent to a load The gating signals are generated by comparing a rectangular reference signal of the amplitude Ar with triangular carrier wave of amplitude Ac, By varying Ar from 0 to Ac, the pulse width can be varied from 0 to $100 \%$. The ratio of Ar to Ac is the control variable and defined as the modulation index.

The frequency of the triangular voltage (fs, carrier frequency) determines theconverter switching frequency and the frequency of the control voltages determinethe fundamental frequency of the converter voltage f1, modulating frequency).Hence, modulating frequency is equal to supply frequency in STATCOM.

Reactive power of STATCOM is varied by controlling the modulation index. Modulation signal isobtained by changing the phase angle and amplitude of this fixed amplitude sinewave.

Thus by varying the modulation index PWM generator will produce suitable firing signals to the switches in VSC and generate required voltage at the STATCOM terminal there by enabling exchange of reactive power between STATCOM and grid, hence enhancing transient stability.

\section{Results and Discussions}

Simulation was done by using MATLAB Simulink. Here we take 33KV grid and designed a suitable STATCOM .fuzzy logic was used for controlling STATCOM. PLL was used for synchronising the control unit with power system. Synchronous rotating frame was used for designing control circuit. A load is suddenly connected at 0.2 second, suddenly voltage at the grid drops to a lower value. To compensate for voltage drop at the grid STATCOM will adjust its voltage such that it will inject sufficient reactive power and return to stable state from the graph we can see that voltage the grid returns to its nominal value at .25 second, thus enhancing transient stability at the grid.

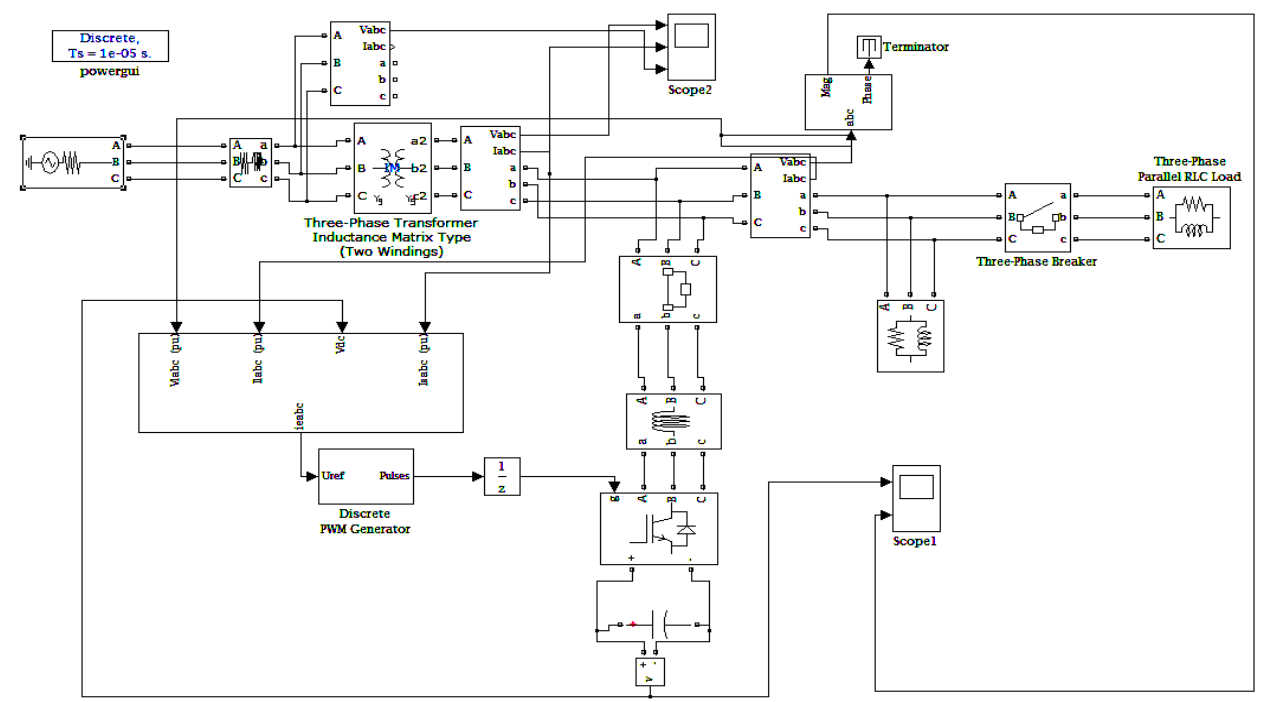

Figure 11:

STATCOM connected to $33 \mathrm{KV}$ grid

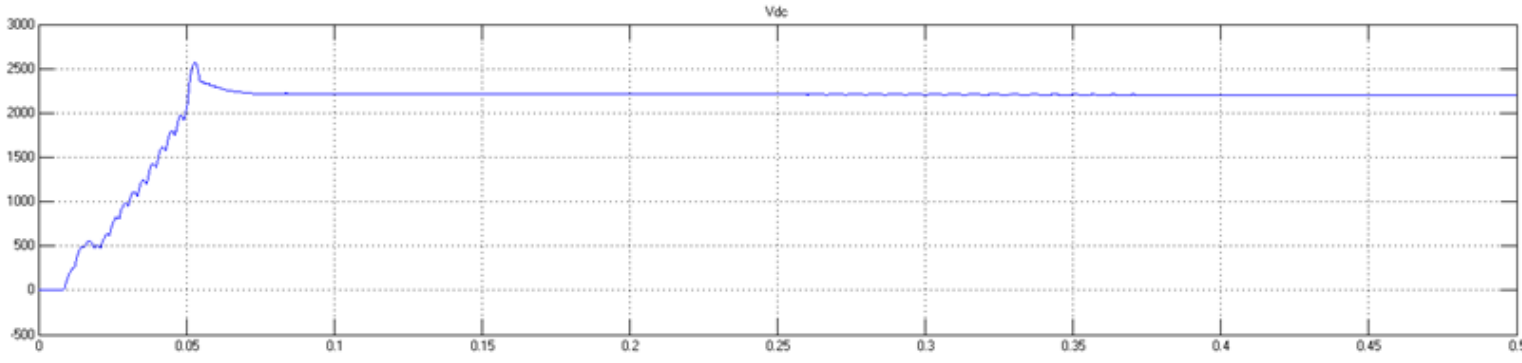

Fig 12: Voltage across capacitor connected to STATCOM 


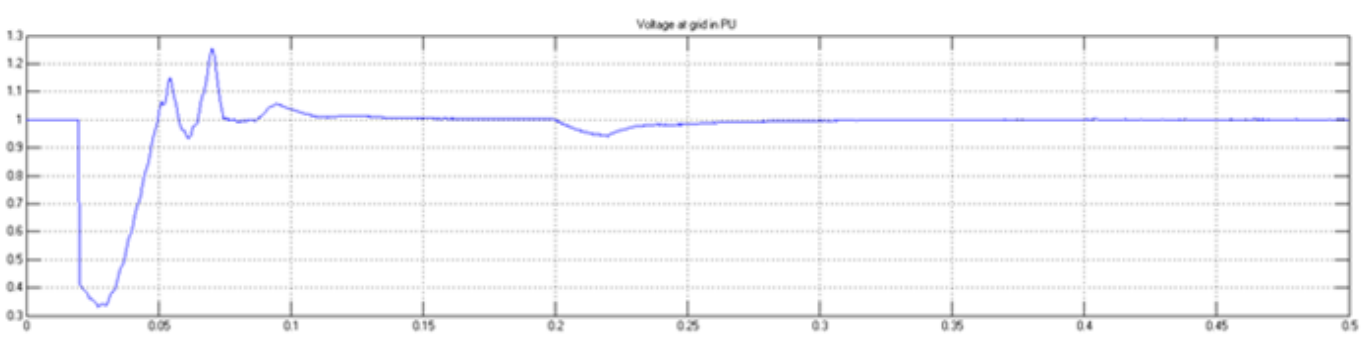

Fig 13: Grid voltage

\section{Conclusion}

The main objective of the proposed system is to develop a circuit for enhancing transient stability at 33KV grid. Fuzzy logic controller was used in controlling STATCOM.It was found that mathematical modelling in synchronous rotating frame reduces the circuit complexity.PLL have successfully synchronise the control unit with the grid parameter The experimental results have been analysed with Matlab simulation.Simulation results analysis has shown that the proposed controller has fast dynamic response, high accuracy of tracking the system stability, and is robust to load sudden variations.

\section{References}

[1] Rajiv Singh, Asheesh Kumar Singh, and Ashutosh Kumar Singh, "Transient Stability Improvement of a FSIG Based Grid Connected wind Farm with the help of a SVC and a STATCOM: A Comparison", International Journal of Computer and Electrical Engineering, February 2012 ,Vol.4, No.1,pp.55-59

[2] PraneshRao, M.L. Crow and Z. Young, "STATCOM control for power system voltage control applications", IEEE Trans. Power Delivery, Oct. 2000Vol.15, No.4, pp.1311-1317

.[3] H. Chen, R. Zhou, Y. Wang, Analysis of voltage stability enhancement by robust nonlinear STATCOM control, Proceedings of the IEEE PES Summer Meeting, 2000, vol. 3, pp. 1924_ 1929.

[4] Pablo Garefa-Gonzalez and Aurelio Garefa-Cerrada, , "Control System for a PWM Based STATCOM", IEEE Transaction Power Delivery, Oct. 2000 Vol. 15, No.4, pp. 1252-1256.

[5] S. K Chung "A Phase Tracking System for Three Phase Utility Interface Inverters", IEEE Transactions on Power Electronics, May 2000 ,Vol. 15, No. 3, pp:431 - 438.

[6] G. Hsieh, and J.C. Hung, "A Phase-locked loop techniques a survey,",IEEE Transactions on Industrial Electronics, Dec. 1996 , Vol. 43, No. 6, pp:609- 615 .

[7] J. D. Ainsworth, "Phase locked loop oscillator - A new control system for controlled static converters," IEEE Power Apparat. Syst., Mar. 1968,vol. PAS-87, pp. 859-865

[8] M. Karimi-Ghartemani, M.R. Iravani "A method for synchronization of power electronic converters in polluted and variablefrequency environments", IEEE Transactions on Power Systems, Aug. 2004, Vol. 19, No. 3, pp:1263- 1270.

[9] C.C. Lee ''Fuzzy Logic in control systems', IEEE Transaction on system Man Cybernetics', Vol. SMC-20, 1990, PP.1378-1384.

[10] K.L. El-Metwally and O.P. Malik, "Fuzzy Logic Power System Stabilizer", IEE Proceedings- Generation, Transmission, Distribution, May 1995,Vol. 142, No. 3, , pp 277-281.

[11] C.C. Lee, "Fuzzy Logic in Control Systems: Fuzzy Logic Controller, Parts I \& II", IEEE Transactions on Systems, Man and Cybernetics, March/April, 1990, Vol. 20, No. 2,pp 404-435.

\section{Author Profile}

Anil Antony P. -He hasreceived the B.Tech degree in Electrical and Electronics Engineering from Jyothi engineering college, Trissur, Kerala, India under University of Calicut in 2008 and currently perusing M.E. in Power Systems Engineeringfrom Paavai Engineering College,Namakkal, Tamil Nadu, India under Anna University, Chennai (2011-2013). During 2009-2011, he has worked as Lecturer in EEE Department under University of Calicut, Kerala, India.

R.PUNITHARAJI-She hasreceived M.E. in Power Systems Engineering from Sona College of Technologyand currently working as Assistant Professor in EEE Department in Paavai Engineering College, Namakkal, Tamil Nadu, India under Anna university, Chennai 